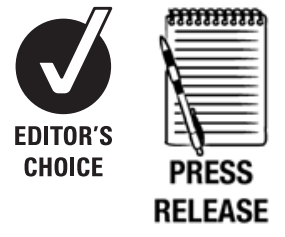

See Editorial, p 92

${ }^{1}$ Institute of Occupational and Environmental Medicine, School of Health and Population Sciences, University of Birmingham, Birmingham, UK ${ }^{2}$ Metroeconomica, University of Bath, UK

${ }^{3}$ Institute of Occupational Medicine, Edinburgh, UK

\section{Correspondence to} Jon G Ayres, Institute of Occupational and Environmental Medicine, School of Health and Population Sciences, University of Birmingham, Birmingham B15 2TT, UK; j.g.ayres@bham.ac.uk

Received 8 February 2010 Accepted 16 September 2010 Published Online First 21 November 2010

\title{
Costs of occupational asthma in the UK
}

\author{
Jon G Ayres, ${ }^{1}$ Richard Boyd, ${ }^{2}$ Hilary Cowie, ${ }^{3}$ \\ J Fintan Hurley ${ }^{3}$
}

\begin{abstract}
Objectives To estimate the social costs of occupational asthma in the UK.

Methods A desk-top approach using cost-of-illness methodology was employed, defining direct and indirect lifetime costs for six scenarios: a male and a female worker each exposed to isocyanates, latex and biocides (eg, glutaraldehyde) or flour. The numbers of new cases annually in each industry were estimated from Survey of Work-related and Occupational Respiratory Disease (SWORD) data. The main outcome measure was the current value total working lifetime costs of new cases annually for each scenario.
\end{abstract}

Results Assuming 209 new cases of occupational asthma in the six scenarios in the year 2003, the present value total lifetime costs were estimated to be $£ 25.3-27.3$ million (2004 prices). Grossing up for all estimated cases of occupational asthma in the UK in 2003, this came to $£ 70-100$ million. About $49 \%$ of these costs were borne by the individual, $48 \%$ by the state and $3 \%$ by the employer.

Conclusions The cost to society of occupational asthma in the UK is high. Given that the number of newly diagnosed cases is likely to be underestimated by at least one-third, these costs may be as large as £95-135 million. Each year a new stream of lifetime costs will be added as a newly diagnosed cohort is identified. Approaches to reduce the burden of occupational asthma have a strong economic justification. However, the economic burden falls on the state and the individual, not on the employer. The incentive for employers to act is thus weak.

\section{BACKGROUND}

Occupational asthma is common with around 3000 new cases diagnosed annually in the UK, but it remains underdiagnosed. ${ }^{1}$ A diagnosis of occupational asthma has major implications for the individual, their family, the state and the employer. The individual may have to leave a well-paid job for one that is less well-paid, leave the workforce completely or remain in the same job and run the risk of worsening asthma, ${ }^{1}$ which may have considerable social and economic implications. Employers may suffer financially from loss of a skilled worker (thus needing to employ and train a replacement) and/or through introduction of expensive exposure controls in the workplace. ${ }^{1}$

The NHS costs of asthma in the UK have been estimated at around $£ 750$ million per annum (2004 prices $)^{23}$ while estimates from other countries vary, largely because of different approaches to costing. $^{4-9}$ Costs increase with asthma severity, ${ }^{10-12}$ those for mild asthma being about half those for moderate asthma, and severe asthma costing about 2.5 times more than moderate asthma. There is less information on the costs of occupational asthma. The total annual costs of occupational asthma in the USA have been estimated at $£ 1.3$ billion, threequarters being direct costs. ${ }^{13}$ For the affected individual, loss of income from having to change jobs is significant, income loss estimates ranging from $22 \%$ to $50 \%{ }^{14-16}$ with $20-80 \%$ of those workers changing jobs suffering some loss of income. ${ }^{14-17}$ Those removed from exposure show greater income loss. ${ }^{16}$ However, those in higher socioeconomic groups find it easier to diversify into related careers, ${ }^{18}$ while one Canadian study reported that around one-fifth of individuals reporting income loss have this at least partly offset by receipt of permanent disability benefit. ${ }^{16}$ In a UK study, disability benefits received by 205 individuals with occupational asthma through to retirement age have been estimated at about $£ 1.8$ million and the cost of their lost work potential at $£ 5-10$ million. ${ }^{19}$

The Health and Safety Executive (HSE) has estimated that, in the UK over a 10-year period, assuming 3000 new cases of occupational asthma annually, the cost of occupational asthma is $£ 1160$ million although this estimate was based on a number of assumptions where evidence was limited. ${ }^{20}$

The aim of this study was to undertake a scenario-based estimation of the social costs of occupational asthma in the UK, taking into consideration the total costs of the disease over the lifetime of affected individuals.

\section{METHODS}

A literature review of the costs of asthma and of occupational asthma along with the costs of related impacts was first undertaken. This was limited to the English literature since 1990 that contained explicit descriptions of the methods of economic valuation used. Information from this review was used to inform the second component of the study which comprised a desk-top 'cost-of-illness' study to estimate the costs of occupational asthma in the UK. This second phase comprised construction of an evidence-based model of new occurrence/diagnosis of occupational asthma to predict the effects on an individual's ability to work and their wider life, including use of health services. It was based on a hypothetical male and a female employee developing occupational asthma having been exposed to one of three typical exposures: (1) isocyanates, (2) latex or glutaraldehyde (essentially healthcare workers) or (3) flour or grain, giving six separate scenarios. The third stage involved putting monetary values on the predicted effects attributable to occupational asthma. The costs were attributed separately to the individual, the employer and the state. A full description of the methodology can be found on the HSE website. ${ }^{21}$ 
Using data from the Survey of Work-related and Occupational Respiratory Disease (SWORD) scheme $e^{22}$ that is used by the HSE for following trends in occupational lung disease in the UK, the likely number of individuals developing occupational asthma in a given year was estimated and then extrapolated to estimate the total affected number of individuals in the UK. Data from the UK Labour Force Survey were used to define the respective populations of exposed workers, the approach used in SWORD, and total lifetime (direct and indirect) costs for each of the case study workers were generated using the following equation:

$$
\text { PVTC }_{\mathrm{UK}}^{n}=\sum^{\alpha} \sum^{g} \sum^{0} \operatorname{PVALCC}_{\mathrm{ago}}^{n} \times \mathrm{NC}_{\mathrm{ago}}^{n}
$$

where $a$ is the sensitising (or causative) agent, $g$ is gender, $o$ is occupation, PVTC $_{\mathrm{UK}}^{n}$ is the present value total cost of new incident cases of occupational asthma in Great Britain in year $n$ where $n$ is the year in which the latest new incident data for occupational asthma are available (in this case 2003), $\mathrm{NC}_{\mathrm{ago}}^{n}$ is the number ofnew cases of occupational asthma assessed in year $n$ from exposure to agent $a$ by individual of gender $g$ and occupation o, PVALCC ${ }_{\text {ago }}^{n}$ is the present value (weighted average) total lifetime cost per case of occupational asthma due to individual of gender $g$ and occupation $o$ being exposed to agent a (weighted average lifetime cost between 'survivors' and 'non-survivors').

Costs incurred by the individual, employers and taxpayers (or government) were separately assessed, the sum of these being taken as the social cost of occupational asthma.

\section{Direct costs}

These were defined as the cost of using healthcare resources to diagnose, treat and rehabilitate workers suffering from occupational asthma, plus non-medical costs incurred by the affected worker. Healthcare costs incurred by the NHS were distinguished from those incurred by the individual. Additional expenditure made by individuals because of occupational asthma, and by the government in administering relevant benefits (paid while the individual is of working age), were also considered. The costs of treating occupational asthma were assumed to be the same as for non-occupational asthma. Specific costs were calculated with upper and lower bounds to allow worst and best case scenarios to be addressed. The unit values used to assess direct costs are summarised in table 1 .

\section{Indirect costs}

For the individual, indirect costs of occupational asthma comprise lost income and 'human costs' from the pain and suffering experienced by the affected worker, and the grief experienced by family and friends. Lost income is affected by an individual's employment status, depending on whether the patient after diagnosis has returned to work with the same employer, either performing the same job or switching jobs, or

Table 1 Breakdown of direct cost estimates per patient

\begin{tabular}{ll}
\hline Planned general practice visits & $£ 14-19$ \\
Unplanned general practice visits & $£ 16-27$ \\
Annual spend on medication & $£ 3-38$ \\
Average annual cost of hospital inpatient services & $£ 63-137$ \\
Annual average costs of outpatient services & $£ 9-15$ \\
Annual savings in commuting costs as a result of being off sick & $£ 15-21^{*}$ \\
Annual average travel costs to engage healthcare services & $£ 8$ \\
Administration costs for administering industrial injuries benefit (men) & $£ 378$ \\
Administration costs for administering industrial injuries benefit (women) & $£ 371$ \\
\hline
\end{tabular}

*Assuming 3.5 and 4.7 days sick leave per year, respectively. whether changing employer or retiring from the labour force. Separately for the three sensitising agents, the gross annual salary of the average exposed male and female worker was calculated using the 2004 New Earnings Survey for the UK, deducting income tax payments and employee National Insurance contributions to derive the net annual salary and making certain assumptions (box 1). The reduction in net annual salary provides a measure of loss to the individual after allowing for any benefits received. 'Human costs' were approximated using values from willingness-to-pay studies of health outcomes relevant to occupational asthma. ${ }^{21}$

For the employer, indirect costs were defined as the opportunity cost of foregone productivity. Three categories of indirect costs to employers were identified-namely, costs arising from sickness absence, costs of labour turnover and compensation and insurance costs. The costs of workplace modification were not estimated as such costs are very site-specific and are largely one-off, nor were the costs of law suits or the costs of insurance assessed. Moreover, workplace modifications are a mitigation measure and, strictly speaking, a cost of reducing the burden of the disease and not a cost of the disease itself. As a consequence, overall employer costs will have been underestimated although, when considering all relevant employers across the UK, probably only to a small degree. The cost of workplace visits by the HSE was likewise not estimated because of their site specificity and unpredictability.

\section{Total costs}

The direct and indirect costs estimated above are annual costs, with the exception of labour turnover and premature mortality, both of which are one-off non-recurring costs. When a worker is diagnosed with occupational asthma, a stream of annual costs is generated over time. To capture the total cost of a new case of occupational asthma, these annual costs were summed by

\section{Box 1 Assumptions made in determining indirect costs}

1. In $25 \%$ of cases the individual will remain with the same employer, performing the same job.

- That $30 \%$ of these individuals will experience a reduction in take home salary of $20 \%$.

2. In $25 \%$ of cases the individual will remain with the same employer, but switch jobs.

- That $20 \%$ of these individuals will experience a reduction in take-home salary of $20 \%$.

3. In $15 \%$ of cases the individual will change employer.*

- That $85 \%$ of these individuals will experience a reduction in take-home salary of $50 \%$.

4. In $15 \%$ of cases the individual will retire from the labour force.

- That $100 \%$ of these individuals will experience a reduction in take-home salary of $100 \%$.

* The studies reviewed show that, at the time of follow-up, about $20 \%$ of individuals with asthma are unemployed. We have assumed that these individuals will ultimately find new employment, although some may retire from the labour force - that is, in $35 \%(15 \%+20 \%)$ of cases the individual is assumed to change employer (and that $85 \%$ of these individuals will experience a reduction in take-home salary of $50 \%$ ). We are therefore overestimating the salary loss if these individuals return to work with the same employer, and underestimating the salary loss if these individuals retire from the labour force. 
Table 2 Direct resource costs of occupational asthma for six case study individuals (2004 prices, £ per person per year)

\begin{tabular}{|c|c|c|c|c|c|c|c|}
\hline \multirow[b]{2}{*}{ Cost component } & \multirow[b]{2}{*}{ Incidence } & \multicolumn{2}{|c|}{ Latex or glutaraldehyde } & \multicolumn{2}{|l|}{ Isocyanates } & \multicolumn{2}{|l|}{ Flour or grain } \\
\hline & & Male & Female & Male & Female & Male & Female \\
\hline General practice (planned) & Taxpayer & +14 to +19 & +14 to +19 & +14 to +19 & +14 to +19 & +14 to +19 & +14 to +19 \\
\hline Medication (net) & Taxpayer & +62 to +107 & +62 to +107 & +62 to +107 & +62 to +107 & +62 to +107 & +62 to +107 \\
\hline Hospital admissions & Taxpayer & +63 to +137 & +63 to +137 & +63 to +137 & +63 to +137 & +63 to +137 & +63 to +137 \\
\hline Outpatient services & Taxpayer & +9 to +13 & +9 to +13 & +9 to +13 & +9 to +13 & +9 to +13 & +9 to +13 \\
\hline DWP admin (SSP) & Taxpayer & +4 to +6 & +4 to +6 & +4 to +6 & +4 to +6 & +4 to +6 & +4 to +6 \\
\hline Subtotal & Taxpayer & +546 to +687 & +539 to +680 & +546 to +687 & +539 to +680 & +546 to +687 & +539 to +680 \\
\hline Prescription charges & Individual & +3 to +38 & +3 to +38 & +3 to +38 & +3 to +38 & +3 to +38 & +3 to +38 \\
\hline Commuting & Individual & -22 to -16 & -13 to -10 & -22 to -16 & -13 to -10 & -22 to -16 & -13 to -10 \\
\hline Additional transport & Individual & +8 & +8 & +8 & +8 & +8 & +8 \\
\hline Subtotal & Individual & -11 to +30 & -2 to +36 & -11 to +30 & -2 to +36 & -11 to +30 & -2 to +36 \\
\hline Total direct resource costs & Society & +535 to +717 & +537 to +716 & +535 to +717 & +537 to +716 & +535 to +717 & +537 to +716 \\
\hline
\end{tabular}

SSP, statutory sick pay; IB, Incapacity Benefit; IIDB, Industrial Injuries Disablement Benefit.

calculating the present value of the cost stream. In calculating the present value lifetime cost of occupational asthma for each of the six case study workers, additional assumptions were made. $^{21}$ Upper and lower bound estimates were calculated incorporating the relevant assumptions made in each case and the results are presented as ranges.

\section{RESULTS}

\section{Numbers of cases of occupational asthma}

The total number of new cases of occupational asthma in Great Britain in 2003 for the three job exposures was estimated to be 2097 male and 21 female workers exposed to latex or glutaraldehyde, 104 male and 4 female workers exposed to isocyanates, and 45 male and 28 female workers exposed to flour or grain.

\section{Direct costs}

Most direct costs did not differ between industry sector or gender, and ranged from $£ 530$ to $£ 715$ per annum per case, with Department of Work and Pensions (DWP) costs for administration of benefits being roughly equivalent to the direct medical costs of treatment. All costs are measured in 2004 prices (table 2).

\section{Indirect costs}

These were much higher than direct costs. Benefits costs to taxpayers were similar for all cases, ranging from $£ 1525$ to $£ 1685$ per annum per case. The highest annual costs were loss of employment income to individuals, with a loss of net annual take home pay after allowing for potential state benefits of between
$£ 1555$ and $£ 5935$ annually per case, with costs to men much higher than to women, reflecting higher annual pay (table 3 ).

Employers' costs were much smaller, ranging from $£ 200$ to $£ 895$ per case. Estimated morbidity costs to individuals, measured by their willingness to pay to avoid quality of life reductions associated with the disease, were even smaller at $£ 145-240$ per year per case (table 3), although these could well be underestimated. Individuals' total willingness-to-pay to avoid the risk of death due to occupational asthma is small, ranging from $£ 70$ to $£ 135$ per year per case.

\section{Total costs}

The total present value costs to society, cumulated over a lifetime and aggregated across the 209 new cases annually in the six scenarios, range from $£ 25.3$ to $£ 27.3$ million, equivalent to between $£ 120 \mathrm{k}$ and $£ 130 \mathrm{k}$ per average case. For male workers the total present value costs range from $£ 19.9$ to $£ 21.4$ million (between $£ 130 \mathrm{k}$ and $£ 135 \mathrm{k}$ per average case) and for female workers from $£ 5.3$ to $£ 5.8$ million (between $£ 100 \mathrm{k}$ and $£ 110 \mathrm{k}$ per average case). Across the six scenarios and assuming that the average worker has moderate symptoms, workers with mild or severe symptoms will cost society between $£ 70 \mathrm{k}$ and $£ 75 \mathrm{k}$ and $£ 320 \mathrm{k}$ and $£ 345 \mathrm{k}$ respectively per worker over their lifetimes (table 4).

The total present value cost for all cases of occupational asthma in the UK, assuming that the costs for other cases would be broadly similar to those in these six scenarios, lies between $£ 71.7$ and $£ 100.1$ million (equivalent to $£ 3.4$ to $£ 4.8$ million per year annualised over the lifetime of individuals affected in 2003)

Table 3 Indirect cost of occupational asthma for six case study individuals (2004 prices, $£$ per person per year)

\begin{tabular}{|c|c|c|c|c|c|c|c|}
\hline \multirow[b]{2}{*}{ Cost component } & \multirow[b]{2}{*}{ Incidence } & \multicolumn{2}{|c|}{ Latex or glutaraldehyde } & \multicolumn{2}{|l|}{ Isocyanates } & \multicolumn{2}{|l|}{ Flour or grain } \\
\hline & & Male & Female & Male & Female & Male & Female \\
\hline Net IB and IIDB & Taxpayer & +1525 & +1610 & +1610 & +1665 & +1635 & +1685 \\
\hline SSP & Taxpayer & +24 to +33 & +24 to +33 & +24 to +33 & +24 to +33 & +24 to +33 & +24 to +33 \\
\hline Subtotal & Taxpayer & +1549 to +1558 & +1634 to +1643 & +1634 to +1643 & +1689 to +1698 & +1659 to +1668 & +1709 to +1718 \\
\hline Reduction in net income & Individual & +5935 & +2535 & +3030 & +1735 & +2535 & +1555 \\
\hline Human costs of ill health (morbidity) & Individual & +145 to +238 & +145 to +238 & +145 to +238 & +145 to +238 & +145 to +238 & +145 to +238 \\
\hline Subtotal & Individual & +6080 to +6173 & +2680 to +2773 & +3175 to +3268 & +1880 to +1973 & +2680 to +2773 & +1700 to +1793 \\
\hline Cost sickness absence & Employer & +256 to +343 & +130 to +174 & +158 to +212 & +109 to +146 & +137 to +183 & +98 to +132 \\
\hline Total indirect costs (annual) & Society & +7885 to +8074 & +4444 to +4590 & +4967 to +5123 & +3678 to +3817 & +4476 to +4624 & +3507 to +3643 \\
\hline Expected mortality cost (one-off cost) & Individual & +90 to +135 & +70 to +105 & +90 to +135 & +70 to +105 & +90 to +135 & +70 to +105 \\
\hline Labour turnover (one-off cost) & Employer & +130 to +520 & +130 to +520 & +93 to +372 & +93 to +372 & +78 to +312 & +78 to +312 \\
\hline Total indirect costs (one-off) & Society & +220 to +655 & +200 to +625 & +183 to +507 & +163 to +477 & +168 to +447 & +148 to +417 \\
\hline
\end{tabular}

SSP, statutory sick pay; IB, Incapacity Benefit; IIDB, Industrial Injuries Disablement Benefit. 
Table 4 Estimated present value lifetime total costs for new cases of occupational asthma in 2003 by gender and sensitising agent $(£ 000$, 2004 prices)

\begin{tabular}{|c|c|c|c|c|}
\hline & Taxpayer & Employer & Individual & Society \\
\hline \multicolumn{5}{|c|}{ Latex or glutaraldehyde } \\
\hline Male & $387-416$ & $38-53$ & $890-919$ & $1314-1387$ \\
\hline \multicolumn{4}{|c|}{ Isocyanates } & $2301-2510$ \\
\hline Male & $5980-6406$ & $343-489$ & $6977-7408$ & $13300-14303$ \\
\hline Female & $241-258$ & $8-11$ & $139-157$ & $388-426$ \\
\hline \multicolumn{5}{|c|}{ Flour and grain } \\
\hline Male & $2619-2803$ & $131-185$ & $2560-2746$ & $5309-5734$ \\
\hline Female & $1700-1820$ & $50-70$ & $892-1011$ & $2642-2901$ \\
\hline
\end{tabular}

for the estimated 631 cases identified in that year. The costs for male workers are more than twice that for female workers, largely reflecting the number of men exposed to relevant agents in the UK and their greater loss of income. Allowing for an underestimation of occupational asthma diagnosis by one-third, the total present value costs to society from all potential cases in 2003 could be between $£ 95$ and $£ 135$ million. Each year will produce a stream of new lifetime costs which will increase year on year, but these are difficult to estimate securely because of changes in exposure controls, management of occupational asthma over time and cohort attrition.

\section{Attribution of costs}

For all 631 incident cases annually (2003 data), the largest burden falls on the individual worker, with present value total costs ranging from $£ 35.5$ to $£ 49.0$ million ( $49 \%$ of the total cost), which is slightly more than that borne by taxpayers. The total present value cost of occupational asthma to employers is relatively small, ranging from $£ 2.0$ to $£ 3.7$ million $(3-4 \%$ of the total cost), which is equivalent to between about $£ 3200$ and $£ 5900$ per average worker diagnosed with occupational asthma, although these costs do not include remedial alterations in the workplace for the reasons set out above (figure 1).

Even if all assumptions are combined to create a 'worse case' for employers, their share of present value total costs only increases to $5-10 \%$.

\section{DISCUSSION}

The study has shown that the overall costs of occupational asthma to the UK are high and significantly greater than those estimated by the HSE. ${ }^{20}$ In addition, the study has shown that the worker and the state bear the great majority of the burden with the employer, even in the most pessimistic case, bearing less than $10 \%$ of the overall costs.

The approach used here to assess the costs of occupational asthma in the UK was chosen to enable estimation of cumulative lifetime costs. A workplace-based individualised approach would have had the problem of being less likely to be extrapolated to the wider population, although it would have allowed more accurate assessment of workplace costs to the employer. Cost-of-illness studies (the approach used in this study) help identify the different components of the social cost of a disease but work on a range of assumptions. ${ }^{23}$ However, the assumptions made in this study are based on UK relevant and validated data in terms of health costs. Previous studies of the costs of asthma have usually used the human capital method, breaking total costs into direct (medical resource) and indirect costs (foregone productivity or opportunity costs), adopting a prevalence-based approach in which all expenditures are estimated for all cases in a specific year without estimating the cumulative effect over consecutive years. ${ }^{24}$ The approach used here allows more accurate assessment of new cases occurring during the time period under consideration, thus enabling a stream of costs relating to a single patient over time to be generated prospectively. This provides a more realistic longer term estimate of costs, and thus the cumulative benefit of assessing the value of interventions to reduce the incidence of new cases ${ }^{24}$ which is most relevant in terms of policy development.

The estimated costs are high and, as the number of newly incident cases of occupational asthma may be underestimated by up to one-third, ${ }^{1}$ the total present value costs to society could be as high as £95-135 million, considerably higher than the HSE's previous estimate ${ }^{21}$ of an average cost per case to society over a 10-year period of $£ 43000$ in 2001. Applying the HSE's cost per case ${ }^{20}$ to the estimated 631 newly incident cases of occupational asthma for 2003 used in this analysis generates an annual cost of close to $£ 2.9$ million (in 2004 prices) compared with the annualised cost from this study of $£ 3.4-4.8$ million. This difference is explained by the additional cost components included in the present study (eg, costs of labour turnover, administration of benefits) and the estimation of lifetime costs in the present study as opposed to costs over a 10-year period. The estimates for 1 year's worth of new cases result in a total present value cost to society of between $£ 71.8$ and $£ 100.0$ million. There is a marked gender difference with the costs for
Figure 1 Incidence of total present value costs to society of reported newly incident cases of occupational asthma in Great Britain in 2003 (2004 prices). Results using $(A)$ the lowest average cost per worker and $(B)$ the highest average cost per worker.

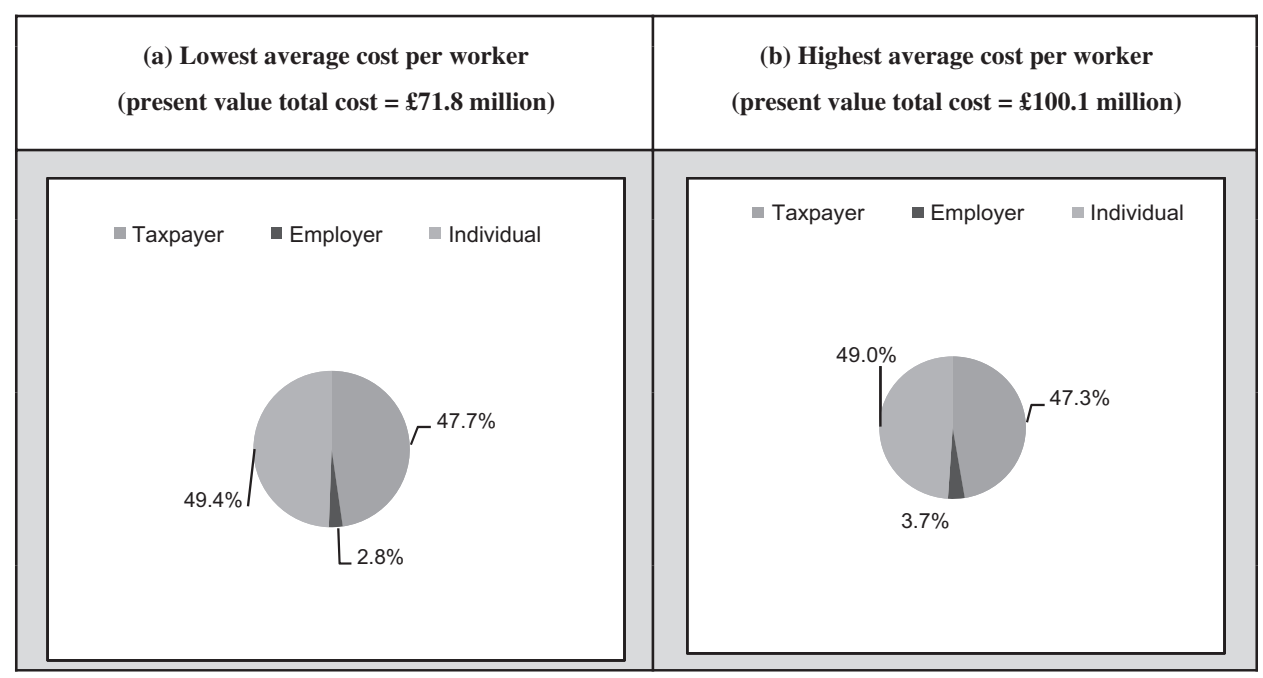


male workers as a group being over twice that for female workers, reflecting the number of men exposed to relevant agents in the UK, as well as their higher income in at-risk occupations.

Poorly controlled asthma, whether primarily due to an occupational exposure or not, is a cause of work loss ${ }^{10} 11$ and is likely to be an important cause of presenteeism. ${ }^{25}$ Developing occupational asthma increases the risk of becoming unemployed, ${ }^{26}$ one study estimating a fall in income of one-third following diagnosis. ${ }^{27}$ Our data would support this, with costs falling heavily on the individual worker and society sharing around $97 \%$ of the overall burden. Both affected employees and the state could benefit considerably if new cases of occupational asthma were reduced with gross gains of between about $£ 70.0$ and $£ 96.8$ million over the lifetime of those workers diagnosed. In contrast, the costs imposed on employers are relatively small, although this estimate does not include costs of workplace modification, litigation or surveillance programmes where instituted. Although employers could save between $£ 3200-5100$ on average over the working life of each employee with occupational asthma, at present there is relatively little financial incentive for employers to intervene to reduce the number of new cases of occupational asthma, despite the fact that significant benefits would accrue to the rest of society. Employers' costs (from civil litigation, modifications to the workplace and work absence) have been reported to be 2.5 times higher for employees with asthma than for non-asthmatic employees (US\$5385 vs US $\$ 2121$, 1998 prices), ${ }^{28}$ while wage replacement costs for lost work days (40\%) account for almost as much as direct medical care costs $(43 \%)$ incurred by the employer. A further employer cost is surveillance programmes and, although it is not clear how many workplaces in the UK where exposure to asthmagenic agents occurs undertake surveillance, it may raise awareness of the likelihood of occupational asthma in both workforce and employers. ${ }^{29}$ We did not cost workplace surveillance in our study, although a recent estimate from the USA using a modelling approach has suggested that annual surveillance using spirometry and a questionnaire could reduce the number of cases at an incremental cost of around US\$24000 per quality-adjusted life year. This equates to a cost per symptom-free day of around US $\$ 13,{ }^{30}$ although these estimates were sensitive to assumptions on sensitisation rates, removal rates and time to diagnosis.

Removal or reduction of exposures to asthmagenic agents in the workplace will therefore result in considerable cost savings: from this analysis the maximum realisable benefit to society would range from $£ 71.8$ to $£ 100.1$ million from avoiding just 1 year's worth of new cases. The findings also suggest that the employer should bear more responsibility for establishing approaches to disease reduction by introduction of appropriate exposure control interventions and changes in work processes, given the modest proportion of the cost they currently bear.

In summary, this pattern of cost burdens for occupational asthma suggests that employers are imposing a large 'external' cost on the rest of society, where costs borne by the individual and the state are not necessarily taken into account by the employer when making decisions that affect the health of the workforce. The presence of such external costs provides a justification for public interventions to reduce the incidence of occupational asthma or to improve health and safety in the workplace generally. However, even if employers take action so that the benefits they accrue just equal their mitigation costs (assuming that employers are fully informed of the costs to be avoided), the level of newly incident cases may still not be acceptable for society as a whole; the residual costs borne by

\section{What is already known on this subject}

Occupational asthma is common but underdiagnosed, with an estimated 3000 new cases diagnosed annually in the UK.

- The costs of occupational asthma to the individual, the state and the employer have not been formally assessed for the UK work force.

\section{What this study adds}

- Each year occupational asthma results in a lifetime cost stream to the UK of between $£ 70$ and 100 million (2004 prices) (€103-147 m).

- The bulk of these costs $(97 \%)$ is borne by the subjects themselves and the state.

- There is an economic case for reducing the burden from occupational asthma.

individuals and the state may justify a much greater level of mitigation than employers are willing to provide in their own interests. New strategies involving government and employers need to be developed to reduce the financial and health burden from occupational asthma.

Funding This study was funded by a competitively tendered project grant from the UK Health and Safety Executive. The study funder discussed and agreed the methodological approach but had no involvement in the interpretation of the data or in the decision to submit the article for publication. All authors confirm that they are independent of the funder with no responsibilities to them.

Competing interests All authors have had grant support but no personal support from the Health and Safety Executive for the submitted work.

Contributors JGA was involved in study design, data interpretation, writing of the manuscript and acts as guarantor for the work. RB was involved in study design, undertook the economic analyses, was involved in data interpretation and writing of the manuscript. JFH and HC were involved in study design, data interpretation and writing of the manuscript.

Provenance and peer review Not commissioned; externally peer reviewed.

\section{REFERENCES}

1. Newman Taylor AJ, Nicholson PJ, Cullinan P, et al. Guidelines for the prevention, identification and management of occupational asthma: evidence review and recommendations. London: British Occupational Health Research Foundation, 2004.

2. Neville R, Hoskins G, Smith B, et al. The economic and human cost of asthma in Scotland. Primary Care Respir J 2003;12:115-19.

3. Gupta R, Sheikh A, Strachan D, et al. Burden of allergic disease in the UK: secondary analyses of national databases. Clin Exp Allergy 2004;34:520-6.

4. Weiss K, Gergen P, Hodgson T. An economic evaluation of asthma in the United States. N Engl J Med 1992;326:862-7.

5. Krahn M, Berka C, Langlois $P$, et al. Direct and indirect costs of asthma in Canada in 1990. Can Med Assoc J 1996:154:821-31.

6. Szucs T, Anderhub H, Rutishauser M. Determinants of health care costs and patterns of care of asthmatic patients in Switzerland. Schweiz Med Wochenschr 2000;130:305-13

7. Szucs T, Anderhub H, Rutishauser M. The economic burden of asthma: direct and indirect costs in Switzerland. Eur Respir J 1999:13:281-6.

8. Smith D, Malone D, Lawson K, et al. A national estimate of the economic costs of asthma. Am J Respir Crit Care Med 1997;156:787-93.

9. Mellis C. Peat J, Bauman A, et al. The costs of asthma in New South Wales. Med J Aust 1990;155:522-8.

10. Serra-Batlles J, Plaza V, Morejon E, et al. Costs of asthma according to the degree of severity. Eur Respir J 1998;12:1322-6.

11. Godard P, Chanex $P$, Siraudin L, et al. Costs of asthma are correlated with severity: a 1-yr prospective study. Eur Respir J 2002;19:61-7.

12. Cisternas $\mathbf{M}$, Blanc $\mathrm{P}$, Yen I, et al. A comprehensive study of the direct and indirect costs of adult asthma. J Allergy Clin Immunol 2003;111:1112-18. 
13. Leigh J, Romano P, Schenker M, et al. Costs of occupational COPD and asthma. Chest 2002;121:264-72.

14. Ameille J, Pairon J, Bayeaux M, et al. Consequences of occupational asthma on employment and financial status: a follow-up study. Eur Respir $J$ 1997; 10:55-8

15. Moscato G, Dellabianca A, Perfetti L, et al. Occupational asthma: a longitudinal study on the clinical and socioeconomic outcome after diagnosis. Chest 1999;115:249-56.

16. Larbanois A, Jamart J, Delwiche J-P, et al. Socioeconomic outcome of subjects experiencing asthma symptoms at work. Eur Respir J 2002;19:1107-13.

17. Vandenplas $\mathbf{O}$, Toren $K$, Blanc $P$. Health and socioeconomic impact of work-related asthma. Eur Respir J 2003:22:689-97.

18. Cannon J, Cullinan P, Newman Taylor A. Consequences of occupational asthma. BMJ 1995:311:602-3.

19. Stenton S, Sandhu P, Hendrick D. Industrial injury benefit for occupational asthma in North East England. BMJ 1995;310:1299-300.

20. Health and Safety Executive. Draft code of practice on occupational asthma: regulatory impact assessment (post consultation). http://www.hse.gov.uk/ria/ chemical/asthma.htm (accessed 10 Jan 2010).

21. Health and Safety Executive. True costs of occupational asthma. Final report. http://www.hse.gov.uk/research/rrpdf/rr474.pdf (accessed 10 Jan 2010).
22. Surveillance of Work-Related and Occupational Respiratory Disease (SWORD). SWORD reporting scheme for occupational lung diseases. http://www. medicine.manchester.ac.uk/oeh/research/workrelatedillhealth/sicknessabsence/thor/ schemes/sword/ (accessed 10 Jan 2010)

23. Ament A, Evers S. Cost-of-illness studies in health care: a comparison of two cases Health Policy 1993:26:29-34.

24. Drummond M, Brandt A, Luce B, et al. Standardising methodologies for economic evaluation of health care: practice, problems and potential. Int J Technol Assess Health Care 1993;9:26-36.

25. Schultz AB, Edington DW. Employee health and presenteeism: a systematic review. J Occup Rehabil 2007;17:547-79.

26. Ross DJ, McDonald JC. Health and employment after a diagnosis of occupational asthma: a descriptive study. Occup Med 1998;48:219-25.

27. Gannon PFJ, Weir DC, Robertson AS, et al. Health, employment and financial outcomes in workers with occupational asthma. Br J Ind Med 1993;50:491-6.

28. Birnbaum H, Berger W, Greenberg P. Direct and indirect costs of asthma to an employer. J Allergy Clin Immunol 2002:109:264-70.

29. Brant A, Berriman J, Sharp C, et al. The changing distribution of occupational asthma: a survey of supermarket bakery workers. Eur Respir J 2005;25:303-8.

30. Wild DM, Redlich CA, Paltiel AD. Surveillance for isocyanate asthma: a model based cost effectiveness analysis. Occup Environ Med 2005;62:743-9.

\section{Pulmonary puzzle}

\section{An unusual case of diaphragm paralysis}

Our patient was a 62-year-old retired accountant of previous good health. He was not taking any medications and had no family history of neurological disease. He was involved in a minor road traffic accident in which his car was shunted from behind. No immediate injuries were sustained; however, he presented to his general practitioner 4 days later with lumbar spine discomfort. He was prescribed a codeine-paracetamol combination pill and diclofenac. Immediately after taking the first dose of these medications he developed severe dizziness and marked vomiting, which culminated in mild haematemesis, indicative of a Mallory-Weiss tear. Subsequently he discovered that he was dyspnoeic lying flat. He presented to his local emergency department with symptoms including marked orthopnoea, and dyspnoea on water immersion past his costal margin and on bending forward.

Physical examination showed gross paradoxical abdominal motion and mild breathlessness when recumbent. Respiratory system, some left basal crackles; cardiovascular system, normal; abdomen, normal; neurology, normal.

Arterial blood gas measurements showed a $\mathrm{PaO}_{2}$ of $11.1 \mathrm{kPa}$ and $\mathrm{a} \mathrm{PaCO}_{2}$ of $5.1 \mathrm{kPa}$. A chest radiograph showed an elevated left hemidiaphragm with some atelectasis above it. A CT pulmonary angiogram excluded any diaphragmatic rupture or pulmonary embolus as an underlying cause of orthopnoea. His sniff nasal inspiratory pressure (SNIP) was measured at $22 \mathrm{~cm}$ $\mathrm{H}_{2} \mathrm{O}$. Detailed testing showed no response to bilateral anterior magnetic phrenic nerve stimulation or to right unilateral phrenic nerve stimulation, with a greatly reduced response to left-sided stimulation (twitch transdiaphragmatic pressure $1.3 \mathrm{~cm} \mathrm{H} \mathrm{H}_{2} \mathrm{O}$; normal $>8 \mathrm{~cm} \mathrm{H} \mathrm{H}_{2} \mathrm{O}$ ). Pulmonary function tests (performed in the erect position) were consistent with diaphragm paralysis, showing a restrictive pattern with mildly reduced carbon monoxide gas transfer ( $\mathrm{TL}_{\mathrm{CO}} 82 \%$ predicted) which became supernormal when corrected for alveolar volume $\left(\mathrm{K}_{\mathrm{CO}} 116 \%\right.$ predicted). Forced vital capacity (FVC) was $64 \%$ predicted, with a forced expiratory volume in $1 \mathrm{~s}\left(\mathrm{FEV}_{1}\right) / \mathrm{FVC}$ ratio of $81 \%$ and stable over the course of 7 months follow-up. Clinic FVC testing in the erect position was 2.8 and 1.5 litres when supine $(54 \%$ reduction). Upright cervical spine MRI revealed minor degenerative changes at C5/6 only. Nerve conduction studies (arms and legs) and needle electromyograph (EMG) examination of the upper limbs were normal.

\section{QUESTIONS}

What was the cause of this patient's diaphragm paralysis and what are the therapeutic options?

See page 168 for the answers

\section{S Freilich, ${ }^{1}$ J C Janssen, ${ }^{1,2}$ M I Polkey ${ }^{1}$}

${ }^{1}$ NIHR Respiratory Biomedical Research Unit, The Royal Brompton Hospital \& Imperial College, London, UK; ${ }^{2}$ Chelsea and Westminster Hospitals, London, UK

Correspondence to Professor M Polkey, Respiratory Muscle Laboratory, Royal Brompton Hospital, London SW3 6NP, UK; m.polkey@rbht.nhs.uk

Funding This project was funded and supported by the NIHR Respiratory Biomedical Research Unit at the Royal Brompton and Harefield NHS Foundation Trust and Imperial College London, who also part funded MIP's salary. The views expressed in this publication are those of the authors and not necessarily those of the NHS, The National Institute for Health Research or the Department of Health.

\section{Competing interests None.}

Patient consent Obtained.

Contributors SF prepared the initial manuscript, JCJ arranged the neurological assessments and commented on the manuscript. MIP managed the patient and reviewed the manuscript.

Provenance and peer review Not commissioned; externally peer reviewed.

Published Online First 21 October 2010

Thorax 2011;66:133. doi:10.1136/thx.2010.145144 